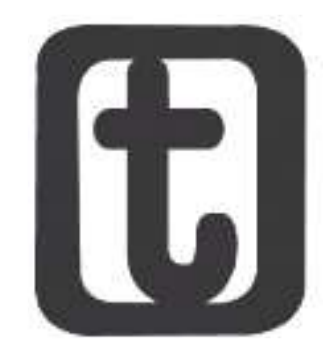

\title{
A LEI DO PISO SALARIAL ESTADUAL: UMA CONQUISTA DOS TRABALHADORES CATARINENSES
}

\author{
States minimum wage's law: an achievement from workers of Santa Catarina
}

\author{
Mauri Antonio da Silva*
}

\section{RESUMO}

O artigo analisa, por meio de estudo bibliográfico, a resistência dos trabalhadores à sua exploração pelo capital. Ao sentirem os efeitos da crise mundial do capitalismo os empresários brasileiros tentam rebaixar os custos com salários para retomar suas altas taxas de lucro e passam a defender o fim dos pisos salariais estaduais de categorias e uma reforma trabalhista para reduzir o valor da força de trabalho. Os resultados de nosso estudo mostram que através de uma ação propositiva do movimento sindical, que ocorre no Estado de Santa Catarina, as centrais sindicais se mobilizaram e conquistaram reajustes do Piso Salarial Estadual, instituído por lei estadual, conquistando ganhos reais acima da inflação oficial.

\section{PALAVRAS-CHAVES}

Exploração; Piso salarial; Regulamentação.

\section{ABSTRACT}

Based on bibliographic research this article analyses the workers resistance to the exploitation of capital. Sensing the effects of the worlds capitalism crises, the Brazilian businessmen attempt to cut the cost from salaries to restart their high profit rates and began to defend the end of minimum wage to the working classes, they also defend a labour reform aiming to reduce the working force value. The study results revealed that through trade unions movement propositions of action that happened in Santa Catarina, the local Trade Union achieved the states minimum wage readjustment, established by federal law, obtaining benefits higher than official inflation rate.

\section{KEYWORDS}

Exploitation; Minimum Wage, Regulation.

\footnotetext{
* Assistente social. Doutor em Serviço Social. Professor temporário do Curso de Serviço Social da Universidade Estadual do Tocantins (Unitins). Unitins, 108 Sul, Alameda 11, Lote 03, Câmpus Graciosa, Cx. Postal 173, CEP 77020-122, Palmas (TO). ORC ID: https://orcid.org/0000-0001-6162-0148. E-mail: <mauri.silva19@gmail.com>.
}

DOI 10.22422/temporalis.2019v19n37p118-133 material em qualquer suporte ou formato, bem como adaptar, transformar e criar a partir deste material para qualquer fim, mesmo que comercial. O licenciante não pode revogar estes direitos desde que você respeite os termos da licença. 


\title{
INTRODUÇÃO
}

\begin{abstract}
A luta pela definição dos valores da força de trabalho atravessa toda a história do capitalismo. Para os capitalistas, o segredo do seu lucro está na extração cada vez

maior da mais-valia produzida pelos trabalhadores que dependem de sua luta organizada por meio dos sindicatos para buscar a valorização da sua força de trabalho que Ihes permita condições de vida digna.
\end{abstract}

O presente artigo produz uma reflexão crítica sobre o assunto, defendendo as regulamentações estatais como estratégia necessária para a proteção do direito dos trabalhadores. Na primeira seção abordaremos a luta histórica pela limitação da exploração dos trabalhadores no capitalismo; na segunda seção realizamos um breve histórico da regulamentação das condições de trabalho no Brasil; na terceira seção analisamos a negociação do Piso Salarial em Santa Catarina expondo sinteticamente os resultados das últimas negociações, que culminaram na aprovação dos novos pisos salariais para os anos de 2015, 2016, 2017, 2018 e 2019. Por fim faremos nossas considerações finais.

\section{A LUTA PELA LIMITAÇÃO DA EXPLORAÇÃO DOS TRABALHADORES NO CAPITALISMO}

No Livro III de O capital, quando Marx aborda O processo global da produção capitalista, encontram-se os fundamentos teóricos para o entendimento de como o desenvolvimento do modo de produção capitalista orientado para a auto-expansão ilimitada sofre frequentes crises - barreiras que procura saltar - em decorrência do excesso de produção em relação ao mercado consumidor. Quando esse excesso de produção não encontra realização no espaço da circulação das mercadorias o capital entra em crise e irá buscar alternativas para superá-la, entre as quais o rebaixamento dos valores que ele paga aos salários dos trabalhadores (MARX, 1983).

O capital, diz Marx (1996, p. 315), “[...] levou séculos, antes de surgir a indústria moderna, para prolongar a jornada de trabalho até seu limite máximo normal e, ultrapassando-o, até ao limite do dia natural de 12 horas".

A partir do nascimento da indústria moderna, no último têrço do século XVIII, essa tendência transformou-se num processo que se desencadeou desmesurado e violento como uma avalanche. Tôdas as fronteiras estabelecidas pela moral e pela natureza, pela idade ou pelo sexo, pelo dia e pela noite foram destruídas. As próprias idéias de dia e de noite, rusticamente simples nos velhos estatutos, desvaneceram tanto que um juiz inglês, em 1860, teve de empregar uma argúcia verdadeiramente talmúdica, para definir juridicamente o que era dia e o que era noite. Eram as orgias do capital (MARX, 1996, p. 316).

De acordo com os estudos de Souto Maior a respeito da jornada de trabalho:

Somente em 1819, com a promulgação do Cotton Mills Act se estabeleceu como um limite de contratação de crianças, a idade de 09 anos. Outras leis posteriores fixaram em nove horas a jornada de trabalho para menores de 18 anos e, em 1833 houve nova diminuição da jornada de trabalho. Para as crianças entre 09 e 13 anos, a jornada passou a ser de 08 horas e para os adolescentes de 13 a 18 anos, de 10 horas (SOUTO MAIOR, 2011, p.162). 
A lei das dez horas conquistada na Inglaterra em 1848 foi um avanço para o século XIX salvando os trabalhadores da degenerescência completa e protegendo sua saúde, mas não era ainda suficiente e nos anos seguintes, o movimento operário mundial lutou pela jornada de 08 horas diárias, sob o lema de 08 horas de trabalho, 08 horas de descanso e 08 horas de lazer, bem como pela conquista do direito a previdência social e a salários dignos.

A intervenção estatal no trato dos problemas sociais esteve presente quando a liberdade individual de trabalho deixou os trabalhadores em total desamparo. Isso foi consequência da revolução industrial que mudou as relações de produção na transição do feudalismo para o capitalismo. Promoveu-se com o capitalismo a acumulação primitiva baseada na expulsão violenta dos homens do campo para as cidades onde suas condições fisiológicas foram aviltadas ao extremo. Com o pauperismo crescente de milhares de trabalhadores, a classe operária nascente respondeu com greves, motins, quebra de máquinas e incêndio de fábricas. O Estado liberal é obrigado a ceder lugar ao Estado intervencionista (SOUTO MAIOR, 2011).

Silva (2013) afirma que a regulação da jornada de trabalho e dos valores do salário ocupa uma posição de centralidade no Direito do Trabalho:

É possível sustentar que o tempo de trabalho mais precisamente sua limitação pela normativa estatal, é parte inseparável da própria gênese do Direito do Trabalho. Daí, porque ainda hoje, os dois temas fundamentais desta disciplina são o salário e a limitação do tempo de trabalho assim como ocorria quando do surgimento das primeiras normas que procuraram estabelecer limites à obtenção do lucro empresarial (SILVA, 2013, p. 62).

A luta dos trabalhadores pela melhoria das suas condições de vida se contrapõe a lógica do capital que "[...] corresponde a crescente pauperização relativa dos trabalhadores" (IAMAMOTO, 2008, p. 24). Em face desta realidade, a luta dos trabalhadores contra o capital é constante para obrigá-lo a aceitar a regulamentação das condições de trabalho, seja por meio de negociações entre as categorias organizadas em suas representações sindicais, que resultam nos acordos e convenções coletivas de trabalho com os empregadores, seja por meio de pressão das centrais sindicais sobre os governos e os parlamentos para que instituam regulações estatais que protegem o conjunto da classe trabalhadora.

Observa-se, ainda, que durante as crises econômicas há uma tendência de descenso dos salários, por isso, Marx, expôs com clareza a importância da luta sindical pela valorização da força de trabalho.

Como sabeis por razões que não vou explicar aqui, a produção capitalista atravessa ciclos periódicos determinados. Passa sucessivamente por uma fase de calma, animação crescente, prosperidade, superprodução, crise e estagnação. Os preços correntes das mercadorias e a taxa corrente de lucro adaptam-se a essas fases, descendo por vezes abaixo das suas médias e voltando a excedê-las noutros períodos [...]. Durante a fase de baixa dos preços do mercado e a de crise e estagnação, o operário, a menos que seja despedido do trabalho, verá sem dúvida diminuir o salário. Para não ser prejudicado, necessitará mesmo, em caso de semelhante queda dos preços do mercado, de discutir com o capitalista para saber em que proporção uma diminuição dos salários se tornou conveniente. Se 
não lutasse por aumentos de salários durante a fase de prosperidade em que se registravam lucros extraordinários, não atingia sequer, na média de um ciclo industrial, o seu salário médio, isto é, o valor do seu trabalho. Representaria o cúmulo da loucura exigir que o operário cujo salário se vê forçosamente afetado pelas fases adversas do ciclo, renunciasse a ser compensado durante as fases prósperas (MARX, 1987, p. 76-77, grifos do autor).

Rossi e Gerab (2009) ensinam que o sindicalismo classista “[...] é um dos canais básicos da luta pela sobrevivência da classe trabalhadora, da população explorada e oprimida. É, também, um instrumento mais próprio a essa classe, uma das classes sociais antagônicas" (ROSSI; GERAB, 2009, p. 81).

A atividade sindical é um degrau adequado para a formação da consciência de classe do proletariado, que por meio de suas lutas por reivindicações imediatas, como melhores salários e condições de trabalho, pode passar a compreender a necessidade da superação do sistema de domínio do capital por meio de uma estratégia de transição socialista.

\section{A REGULAMENTAÇÃO DAS CONDIÇÕES DE TRABALHO NO BRASIL}

No Brasil, as condições de trabalho são regulamentadas pela Consolidação das Leis do Trabalho (CLT) de 1943. Ela codificou as leis que foram conquistadas pela classe operária em suas lutas contra as classes dominantes desde o século XIX até o decorrer das três primeiras décadas do século XX. ${ }^{1}$ Segundo Nascimento, "[...] ela reuniu as leis sobre o direito individual do trabalho, o direito coletivo do trabalho e o direito processual do trabalho" (NASCIMENTO, 2010, p. 103).

Houve marchas e contramarchas na história dos direitos trabalhistas no Brasil, cabendo ressaltar avanços ocorridos durante a Assembleia Nacional Constituinte de 1988 como a redução da jornada de trabalho de 48 para 44 horas semanais, a criação de uma indenização em caso de dispensa arbitrária, a elevação do adicional de horas-extras para o mínimo de 50\%, ampliação da licença-maternidade para 4 meses, a elevação da idade mínima para o trabalho para 14 anos, o reconhecimento das liberdades sindicais, a igualdade de direitos entre trabalhadores urbanos e rurais, e o reconhecimento da seguridade social, constituída pelo tripé assistência, saúde e previdência como direito de todos e dever do Estado.

No entanto, a Constituição Federal de 1988 passou a ser alvo de ataques por parte de governos alinhados ao pensamento neoliberal difundido pelo Banco Mundial e pelo Fundo Monetário Internacional (FMI), órgãos internacionais subordinados ao capital financeiro. As regulações estatais referentes ao trabalho foram sendo alvejadas de modo crescente e com o surgimento da crise capitalista internacional de 2008 novas críticas ao direito do trabalho surgiram, sendo que em 2012, a Confederação Nacional das Indústrias (CNI) lançou um documento com 101 Propostas para Modernização Trabalhista, entre as quais, preconiza o fim dos pisos salariais estaduais para categorias de trabalhadores (CONFEDERAÇÃO NACIONAL DA INDÚSTRIA, 2012).

De acordo com Singer (2016), "[...] o baixo crescimento do PIB em 2012 e certa pressão inflacionária deram o combustível para os argumentos anti-desenvolvimentistas [...]"

${ }^{1}$ Cf. Linhares (1977, p. 33); Mattos (2008, p.14); Koval (1982, p.87); Iamamoto (1982).

Temporalis, Brasília (DF), ano 19, n. 37, p. 118-133, jan./jun. 2019. | ISSN 2238-1856 
(SINGER, 2016, p. 50), sendo que, no “[...]caso dos empresários, teria havido um elemento de maior importância objetiva que pode ter sido a oscilação do lucro". A Confederação Nacional da Indústria (CNI) "vinha argumentando que houve queda generalizada da margem de ganho em 2012, com alguma recuperação em 2013 e nova queda em 2014". Neste contexto, "a perspectiva neoliberal de diminuir os salários e direitos" se tornou atraente para os empresários.

Tratava-se de aumentar a histórica superexploração do trabalhador brasileiro, ou seja, o pagamento de salários abaixo do valor necessário para o trabalhador repor suas energias físicas e espirituais.

Como ensina Marini (2000), a superexploração ocorre pela conjugação de três fatores: a intensificação do trabalho, a prolongação da jornada de trabalho e a expropriação de parte do trabalho necessário ao operário para repor sua força de trabalho. Configura-se, desse modo, um modo de produção fundado exclusivamente na maior exploração do trabalhador e não no desenvolvimento da sua capacidade produtiva. A característica das economias latino-americanas, inclusive o Brasil, é o baixo nível do desenvolvimento das forças produtivas e também o tipo de atividades que se desenvolvem nelas.

No Brasil, a Consolidação das Leis do Trabalho (CLT), no art.76, define o salário mínimo “[...] como a contraprestação mínima devida e paga diretamente pelo empregador a todo trabalhador, destinada à satisfação de determinadas necessidades vitais, que devem ser consideradas na elaboração do cálculo de seu valor [...]", assevera Nascimento (2010, p. 818). A ideia de um salário mínimo representa, para o direito do trabalho, uma intervenção legal do Estado com o objetivo de garantir a defesa de um nível de vida abaixo da qual é impossível o homem ter uma existência digna.

O salário mínimo tem amplitude nacional e o salário profissional é restrito a determinada categoria profissional. A definição do salário mínimo ocorre por iniciativa da Presidência da República que encaminha ao Congresso Nacional a proposta de reajuste do mesmo anualmente. De acordo com a Constituição Federal de 1988 (art. $7^{\circ}$., IV), o valor do salário mínimo deve considerar as necessidades vitais do trabalhador e de sua família, com alimentação, habitação, vestuário, higiene, transporte, educação, lazer, saúde e previdência social.

A partir do ano de 2008, “[...] o salário mínimo passou a ser reajustado com base na variação do INPC apurado desde a correção anterior, acrescido de um ganho real que equivale a variação do PIB de dois anos antes" (DIEESE, 2012, p. 369). Para 2015 o valor do salário mínimo passou a ser $\mathrm{R} \$ 788,00$, conforme decreto presidencial publicado no Diário Oficial da União (DOU), em 30 de dezembro de 2014. A correção representa 8,84\% sobre os $\mathrm{R}$ 724,00 vigente em 2014 e corresponde à variação do Produto Interno Bruto (PIB) em 2013 de 2,5\% e à variação anual do Índice Nacional de Preços ao Consumidor (INPC), que foi calculado pelo IBGE em 2014, estimada em 6,19\% (CARDOSO, 2015).

O aumento do salário mínimo beneficia milhões de brasileiros que tem suas aposentadorias atreladas ao salário mínimo. O peso relativo da massa dos benefícios, equivalentes a até 1 salário mínimo, é de 50,3\% e corresponde a 69,3\% do total de beneficiários (CARDOSO, 2015). No entanto, o valor ainda está longe do ideal constitucional, pois o salário mínimo

Temporalis, Brasília (DF), ano 19, n. 37, p. 118-133, jan./jun. 2019. | ISSN 2238-1856 
necessário, definido para uma família de dois adultos e duas crianças, satisfazerem suas necessidades básicas, pelos cálculos do Departamento Intersindical de Estatísticas e Estudos Socioeconômicos (DIEESE) deveria ser de R\$3.377,62, em maio de 2015 (DIEESE, 2019). Esse valor foi atualizado para $\mathrm{R} \$ 3.928,73$, em janeiro de 2019, que é 3,94 vezes 0 salário mínimo em vigor no ano de 2019, de R\$998,00. ${ }^{2}$

A Lei Complementar (LC) 103/2000 permite aos Estados e ao Distrito Federal o estabelecimento de pisos salariais para categorias, aplicados, sobremaneira para aquelas categorias menos organizadas do ponto de vista sindical que não contam com lei federal, acordos coletivos ou convenções coletivas de trabalho que fixem o piso (BRASIL, 2000).

Nos últimos anos a CNI passou a combater os pisos salariais estaduais de categorias. Os empresários argumentam que são prejudicados pela introdução dos pisos de forma política, "[...] sem qualquer base econômica que sustente a escolha do governador e da Assembleia Estadual em torno da fixação dos valores" (CONFEDERAÇÃO NACIONAL DA INDÚSTRIA, 2012, p. 51).

As propostas do empresariado visam frear as tímidas conquistas da classe trabalhadora, por isso, pressionam pela revisão da política de valorização gradual do salário mínimo; pela ampliação das possibilidades de terceirização das suas atividades e contra a redução da jornada legal de trabalho sem redução de salários.

Na verdade, o que querem os empresários é a manutenção do controle sobre os operários para mantê-los circunscritos a ordem do capital como sempre foi defendido pelos apologistas do capital como o austríaco Friedrich Von Hayek (1899-1992), que foi premiado com o prêmio Nobel de economia de 1974, para o qual o poder dos sindicatos explicava o debilitamento do capitalismo e não as contradições inerentes deste sistema. Para Hayek o Estado deveria suprimir o direito do trabalho, porque os sindicatos não tinham razão de existir e nem de atuar sobre o mercado de trabalho, que deveria regular-se livremente pelo livre "[...] jogo das forças espontâneas do mercado" (VALENCIA, 2010, p. 81).

Segundo a CNI, os pisos salariais estaduais promovem "[...] graves distorções nas estruturas salariais, têm comprometido a competitividade das empresas, os investimentos e a geração de bons empregos, além das finanças públicas dos municípios" (CONFEDERAÇÃO NACIONAL DA INDÚSTRIA, 2012, p. 51).

Com o aumento das taxas de desemprego, sobretudo nos países do capitalismo central que foram mais fortemente atingidos pela crise capitalista que emergiu a partir de 2008 nos Estados Unidos da América e se espalhou pelo mundo, comprimindo os salários para baixo, a burguesia brasileira para poder exportar seus produtos com competitividade vem exigindo um rebaixamento dos custos do trabalho para poder enfrentar seus concorrentes externos que estão com os custos mais baixos, sobretudo os da periferia.

As situações de ataques aos direitos laborais manifestam-se como uma tendência em face da crise econômica que atinge o Brasil, agravada pela política recessiva implantada pelo Governo Federal, que se ancora em endurecimento das regras na concessão de direitos sociais e aumento da taxa de juros (SILVA, 2017).

\footnotetext{
${ }^{2}$ Veja mais em: Salário... (2019).
} 
De acordo com o Dieese (2015a), há poucas esperanças de recuperação no curto prazo. Após o país crescer quase zero $(0,1 \%)$ em 2014, os resultados do primeiro trimestre do ano indicavam que 2015 deveria se encerrar com queda do PIB em cerca de $1 \%$. Ressalta-se que, em 2014, a taxa per capita - a divisão do total de riqueza produzida no país pelo número de habitantes - registrou retração de $0,7 \%$, indicando empobrecimento da população no período.

Após o impeachment da Presidenta Dilma Rousseff, em agosto de 2016, o governo federal aprofunda a política de austeridade fiscal que mergulha o pais na recessão, acelera a privatização da economia e a retirada de direitos sociais por meio da reforma trabalhista, aprovada em 2017, e do congelamento dos investimentos sociais por vinte anos, aprovado em 2016, prometendo a retomada do crescimento. Contudo, a receita liberal resultou em pífios resultados econômicos, no aumento do desemprego e do trabalho precário.

De acordo com o Instituto Brasileiro de Geografia e Estatística (IBGE), a economia brasileira cresceu apenas 1,1\% em 2018 em relação ao ano anterior, tendo chegado ao mesmo patamar do Produto Interno Bruto (PIB) que apresentou no primeiro semestre do ano de 2012. Entre os anos de 2015 e 2016, o PIB apresentou uma variação negativa de $-3,5 \%$ e de $3,6 \%$, respectivamente. Em 2017, o crescimento da economia brasileira foi de 1,1\%. Além do crescimento insignificante em 2018, observa se o fraco desempenho no quarto trimestre do ano, com expansão do PIB de apenas $0,1 \%$ em relação ao trimestre imediatamente anterior (CARDOSO, 2019).

Nesta conjuntura a histórica superexploração da força de trabalho latino-americana, segundo Valencia, se mantém, pois,

É condição preponderante na América Latina, devido às desregulamentações do trabalho, a existência de grandes bolsões de trabalhadores desempregados, sujeitos a condições de superexploração do trabalho, baixos salários, rotação de postos e funções e precarização de emprego (VALENCIA, 2009, p. 179 apud BERTOLO, 2015, p. 228).

No Brasil os salários do setor privado situam-se em uma média de $\mathrm{R} \$ 1.500,00$. Os baixos valores dos salários refletem os efeitos do péssimo desempenho do PIB nos últimos anos, apesar das promessas governamentais de que, a partir da contrarreforma trabalhista, aprovada em 11 de novembro de 2017, flexibilizando os direitos estabelecidos na CLT por meio da livre negociação, a economia e o mercado de trabalho navegariam "[...] de vento em popa". 3 Em 2018, segundo o IBGE, a taxa média de desocupação estimada foi de 12,3\%, pouco abaixo dos $12,7 \%$ de 2017 (CARDOSO, 2019).

\section{A NEGOCIAÇÃO DOS PISOS SALARIAIS EM SANTA CATARINA}

No Estado de Santa Catarina vem sendo realizadas anualmente as negociações entre o empresariado e os trabalhadores, em torno da definição de valores mínimos do Piso

\footnotetext{
3 Sobre a relação entre a crise do capital e as proposições do empresariado para a reforma trabalhista, ver SILVA (2017). Sobre os efeitos da reforma trabalhista no mercado de trabalho, ver TEIXEIRA et al. (2017). Para Severo (2017, p. 44), a Lei 13.467, do início ao fim, nega a proteção ao trabalho, mesmo que seus autores tenham afirmado essa finalidade na exposição de motivos da reforma. Portanto, “[...] suas regras são qualquer coisa, menos normas jurídicas trabalhistas" (SEVERO, 2017, p. 44).
}

Temporalis, Brasília (DF), ano 19, n. 37, p. 118-133, jan./jun. 2019. | ISSN 2238-1856 
Salarial. A conquista do Piso Salarial Estadual foi uma vitória da mobilização das centrais sindicais que, após três anos de pressão sobre a classe empresarial catarinense, conseguiram arrancar a implantação do Piso por meio da aprovação da Lei Complementar 459/2009, que abrange cerca de um milhão de trabalhadores.

Em 2015, pelo quinto ano consecutivo, as centrais sindicais conseguiram negociar com os empresários a renovação do Piso Salarial Estadual, com reajuste médio de 8,84\% em relação ao salário vigente em 2014. Os valores foram acordados entre as centrais sindicais e federações de trabalhadores e as federações patronais. Segundo a Federação dos Comerciários do Estado de Santa Catarina (FECESC, 2015a), após um processo de negociações moroso e difícil em função das diferentes avaliações de conjuntura por parte de empresários e trabalhadores, foi assinado um Termo de Compromisso para os novos pisos. O Termo foi enviado ao governador do Estado que encaminhou o Projeto de Lei à Assembleia Legislativa, onde foi aprovado por unanimidade (FECESC, 2015b).

A manutenção do Piso Salarial Estadual tem sido uma conquista da classe trabalhadora catarinense frente à resistência empresarial em diminuir o grau de exploração da força de trabalho.

A Lei Complementar que estabelece o Piso Salarial em Santa Catarina (LC 459/2009) prevê quatro faixas salariais, que tiveram um índice de reajuste que variaram de $8,74 \%$ a $8,99 \% .{ }^{4} \mathrm{E}$ importante observar que os ganhos reais acompanhavam uma trajetória de melhoria nas negociações de salários por parte dos sindicatos, as quais foram apoiadas por uma crescente mobilização dos trabalhadores, que de acordo com os informes preliminares do Sistema de Acompanhamento de Greves - SAG do DIEESE, realizaram 1901 greves em 2013 (DIEESE, 2015b, grifos nossos). Os índices negociados foram superiores ao índice da inflação de 2014 que ficou em 6,23\% como demonstra a análise da tabela do Dieese abaixo:

\footnotetext{
${ }^{4}$ As categorias de trabalhadores abrangidas em cada faixa são as seguintes: I - na agricultura e na pecuária; nas indústrias extrativas e beneficiamento; em empresas de pesca e aquicultura; empregados domésticos; nas indústrias da construção civil; nas indústrias de instrumentos musicais e brinquedos; em estabelecimentos hípicos; e empregados motociclistas, motoboys, e do transporte em geral, excetuando-se os motoristas. II - nas indústrias do vestuário e calçado; nas indústrias de fiação e tecelagem; nas indústrias de artefatos de couro; nas indústrias do papel, papelão e cortiça; em empresas distribuidoras e vendedoras de jornais e revistas e empregados em bancas, vendedores ambulantes de jornais e revistas; empregados da administração das empresas proprietárias de jornais e revistas; empregados em empresas de comunicações e telemarketing; e nas indústrias do mobiliário. III - nas indústrias químicas e farmacêuticas; nas indústrias cinematográficas; nas indústrias da alimentação; empregados no comércio em geral; e empregados de agentes autônomos do comércio. IV - nas indústrias metalúrgicas, mecânicas e de material elétrico; nas indústrias gráficas; nas indústrias de vidros, cristais, espelhos, cerâmica de louça e porcelana; nas indústrias de artefatos de borracha; em empresas de seguros privados e capitalização e de agentes autônomos de seguros privados e de crédito; em edifícios e condomínios residenciais, comerciais e similares, em turismo e hospitalidade; nas indústrias de joalheria e lapidação de pedras preciosas; auxiliares em administração escolar (empregados de estabelecimentos de ensino); empregados em estabelecimento de cultura; empregados em processamento de dados; e empregados motoristas do transporte em geral; empregados em estabelecimentos de serviços de saúde (SANTA CATARINA, 2009).
}

Temporalis, Brasília (DF), ano 19, n. 37, p. 118-133, jan./jun. 2019. | ISSN 2238-1856 
Tabela 1. Pisos negociados em Santa Catarina para o ano de 2015.

\begin{tabular}{|c|c|c|c|c|}
\hline Faixas salariais & $\begin{array}{l}\text { Piso em } 2014 \\
\text { (R\$) }\end{array}$ & $\begin{array}{l}\text { Piso negociado } \\
\text { (R\$) }\end{array}$ & $\begin{array}{c}\text { Reajuste } \\
\text { nominal (\%) }\end{array}$ & $\begin{array}{c}\text { Ganho Real* } \\
\text { (\%) }\end{array}$ \\
\hline Primeira faixa & 835,00 & 908,00 & 8,74 & 2,37 \\
\hline Segunda faixa & 867,00 & 943,00 & 8,77 & 2,39 \\
\hline Terceira faixa & 912,00 & 994,00 & 8,99 & 2,60 \\
\hline Quarta faixa & 957,00 & $1.042,00$ & 8,88 & 2,50 \\
\hline \multicolumn{5}{|c|}{$\begin{array}{l}\text { * Percentual acima do INPC, que foi de 6,23\%. } \\
\text { Fonte: DIEESE apud FECESC (2015b). }\end{array}$} \\
\hline
\end{tabular}

Para Cardoso (2015), a exemplo do que ocorre com o salário mínimo nacional, o incremento de massa salarial proporcionado pelos novos valores do Piso Estadual é direcionado ao consumo dos artigos de primeira necessidade nas áreas do vestuário, alimentos e transporte, fortalecendo toda a economia de Santa Catarina, por isso a continuidade dos acordos em torno dessa política salarial é fundamental e viável para todos:

Os trabalhadores de praticamente todos os setores vêm obtendo ganhos reais nas suas negociações específicas, o que é positivo para toda a economia. 0 aumento da renda do trabalhador favorece o crescimento industrial e o comércio, como vem ocorrendo nos últimos anos em Santa Catarina. Segundo o Índice de Atividade Econômica Regional de Santa Catarina (IBCR-SC), calculado pelo Banco Central, a economia catarinense cresceu 2,7\%, nos oito primeiros meses de 2014, ante variações de $0,6 \%$ no mesmo indicador na Região Sul e de -0,1\% no Brasil. Ademais, o mercado de trabalho em Santa Catarina segue em razoável trajetória. A taxa acumulada de crescimento do emprego formal em Santa Catarina atingiu $71,2 \%$ de 2003 a 2013 (60,1\% no Sul e 65,7\% no país) de acordo com a Relação Anual de Informações Sociais (Rais) do Ministério do Trabalho e Emprego (MTE). Segundo a Pesquisa Nacional por Amostra de Domicílios (PNAD), a taxa de desocupação do estado atingiu 3,2\% em 2013 (contra 4,1\% no Sul e 6,6\% no Brasil). No período mais recente, a tendência continuou sendo a mesma. Até novembro, em 12 meses, o emprego formal em Santa Catarina cresceu 2,68\% (54.112 mil novos postos), contra $1 \%$ no Brasil, $1,6 \%$ no Paraná e $1,1 \%$ no Rio Grande do Sul (CARDOSO, 2015, p. 1).

Assim, evidencia-se equivocada a tese dos empresários quanto a possível piora da economia em face de um aumento dos pisos estaduais de salários. Pelos dados apresentados por Cardoso, os reajustes dos pisos salariais em Santa Catarina provocaram melhorias no mercado de trabalho e na economia catarinense. Sabe-se também que um aumento do salário mínimo nacional e dos pisos salariais do Estado amplia o consumo e a arrecadação tributária, o que permite uma melhora das contas públicas e um maior volume de recursos que o Estado necessita para implementar investimentos em infraestrutura e políticas sociais.

Nos anos seguintes os trabalhadores continuaram a luta pela valorização do salário mínimo estadual, em busca da proteção das suas condições de vida aviltadas pela exploração do capital.

Em 2016, depois de uma longa negociação na tarde do dia 22 de março, representantes dos trabalhadores e dos empresários definiram o reajuste para as quatro faixas salariais do Piso 
Estadual. Os valores negociados para as 4 faixas do piso foram: $\mathrm{R} \$ 1.009,00$ para a $1^{\mathrm{a}}$ faixa; $R \$ 1.048,00$ a $2^{a}$ faixa; $R \$ 1.104,00$ a $3^{\text {a }}$ faixa e $R \$ 1.158,00$ a $4^{\text {a }}$ faixa, com reajustes respectivos de 11,12\%, 11,12\%, 11,06\%, 11,12\%, em relação aos pisos de 2016 (FECESC, 2016).

Em 2 de março de 2017, a negociação entre os representantes dos trabalhadores e dos empresários, fixou um acordo que "agradou mais aos empresários do que aos trabalhadores por abranger, em média, as perdas com a inflação". Os valores do Piso Salarial Estadual em 2017 para as quatro faixas foram estabelecidos desse modo: $1^{\text {a }}$ faixa: $\mathrm{R} \$ 1.078,00 ; 2^{\mathrm{a}}$ faixa: $\mathrm{R} \$ 1.119,00 ; 3^{\mathrm{a}}$ faixa $\mathrm{R} \$ 1.179,00,4^{\mathrm{a}}$ faixa: $\mathrm{R} \$ 1.235,00$. O resultado foi insatisfatório para os trabalhadores por não terem alcançado ganhos reais que vinham sendo alcançados ao longo das últimas negociações e com muita luta impediram que se estabelecesse valores abaixo da inflação (FECESC, 2017).

Em negociação realizada no dia 18 de janeiro de 2018, os representantes dos empresários e dos trabalhadores chegaram a um acordo para definir a proposta de reajuste do Piso Salarial Estadual para 2018. O índice alcançado foi de 2,95\% (valor acima do INPC de 2017, que foi de 2,07\%). Deste modo, as quatro faixas salariais previstas no Piso passaram a ser, a partir de janeiro de 2018, de: $1^{a}$ faixa: $R \$ 1.110,00 ; 2^{a}$ faixa: $R \$ 1.152,00 ; 3^{\text {a }}$ faixa: $R \$ 1.214,00$; e $4^{\text {a }}$ faixa: $R \$ 1.271,00$ (FECESC, 2018).

No ano de 2019 foi estabelecido um reajuste de 4,3\%, índice abaixo do índice da correção do salário mínimo nacional, que foi estabelecido em 4,61\% e superior ao percentual do INPC, que foi de $3,43 \%$, de acordo com o IBGE. 5

O resultado das negociações entre os representantes dos patrões e empregados foi encaminhado ao governador do Estado, para que este o convertesse em projeto de lei e o encaminhasse à Assembleia Legislativa do Estado (ALESC), para apreciação dos Deputados Estaduais, retornando em seguida para sanção do governador do Estado.

Após o final das negociações, além de solicitarem a audiência com o governador, as entidades dos trabalhadores e também as patronais, visitaram o líder do governo da Assembleia, deputado Coronel Mocellin (PSL), e os líderes de bancada, para sensibilizar os deputados estaduais sobre a necessidade de agilizar o processo de criação da Lei que formaliza o reajuste do Piso Salarial Estadual (FECESC, 2019a).

A conclusão das negociações foi razoável, diante do contexto econômico nacional. Como analisou o diretor sindical do Dieese, Ivo Castanheira, que coordena a comissão que representa os trabalhadores, "[...] esta negociação tem sido muito importante para o exercício de democracia. A representatividade dos dois lados é significativa o que demonstra a importância do processo" (HOMRICH, 2019, p.1). Portanto, o significado é muito grande para os trabalhadores de Santa Catarina, pois são poucos os estados que têm um Piso Estadual, que resulta de uma luta sindical pela valorização da negociação coletiva de trabalho, para ampliar o grau de proteção social do trabalho, incrementar a renda dos trabalhadores e estimular a economia estadual (HOMRICH, 2019).

Na totalidade são quatro faixas que compõem o Piso Salarial Estadual. Observa-se abaixo, como ficam os salários desses trabalhadores com o reajuste negociado, aprovado na

\footnotetext{
${ }^{5}$ Cf. IBGE (2019).
}

Temporalis, Brasília (DF), ano 19, n. 37, p. 118-133, jan./jun. 2019. | ISSN 2238-1856 
Assembleia Legislativa e sancionado, em 05 de abril de 2019, pelo governador do Estado de Santa Catarina, com efeito retroativo a janeiro de 2019 (FECESC, 2019b; 2019C).

Tabela 2. Pisos negociados em Santa Catarina para o ano de 2019

\begin{tabular}{|c|c|c|c|c|}
\hline $\begin{array}{c}\text { Faixas } \\
\text { salariais }\end{array}$ & $\begin{array}{c}\text { Piso em } \\
\mathbf{2 0 1 8}(\mathbf{R} \mathbf{\text { ) }})\end{array}$ & $\begin{array}{c}\text { Piso } \\
\text { negociado } \\
(\mathbf{R} \mathbf{)}\end{array}$ & $\begin{array}{c}\text { Reajuste } \\
\text { nominal (\%) }\end{array}$ & $\begin{array}{c}\text { Ganho Real } \\
\text { acima do INPC } \\
(\%)\end{array}$ \\
\hline Primeira faixa & $1.110,00$ & $1.158,00$ & 4,32 & 0,89 \\
\hline Segunda faixa & $1.152,00$ & $1.201,00$ & 4,25 & 0,82 \\
\hline Terceira faixa & $1.214,00$ & $1.267,00$ & 4,37 & 0.84 \\
\hline Quarta faixa & $1.271,00$ & $1.325,00$ & 4,24 & 0,81 \\
\hline
\end{tabular}

Fonte: HOMRICH (2019). Elaboração nossa com base no INPC (IBGE) de 3,43\% em 2018.

Os reajustes acima da inflação foram possíveis devido a mobilização das centrais sindicais e ao esforço de qualificação das negociações por meio de argumentos sólidos, ressalvando-se os resultados de 2017 que foram insatisfatórios para os trabalhadores, revelando a falta de sensibilidade das entidades patronais para a necessidade de estabelecer valores salariais que melhorem as condições de vida da classe trabalhadora e fortaleçam o mercado interno como forma de gerar empregos de qualidade e reaquecer a economia nacional e estadual.

Milhares de trabalhadores de categorias profissionais com fraca organização sindical, como é o caso dos trabalhadores domésticos conseguem uma melhoria no seu padrão salarial em função dessas negociações que são anualmente coordenadas pelas direções sindicais.

Os sindicatos que estão na base das centrais sindicais podem ampliar o piso por meio de negociações coletivas, assegurando aumentos reais mais expressivos e impedindo a queda dos salários e o aumento das desigualdades sociais no País, como mostram recentes estudos da Fundação Getúlio Vargas, que relacionam essa queda ao aumento do desemprego. ${ }^{6}$

\section{CONSIDERAÇÕES FINAIS}

A crise capitalista mundial chegou ao Brasil trazendo problemas angustiantes para os trabalhadores: dispensas, desemprego, fechamento de empresas, ataques aos salários e aos direitos sociais, aceleração dos ritmos de trabalho, ataques aos direitos sindicais.

\footnotetext{
${ }^{6}$ De acordo com o FGV Social no seu levantamento "Qual foi o impacto da crise sobre a pobreza e a distribuição de renda?", ocorreu o aumento da pobreza e da desigualdade até o segundo trimestre de 2018. Hoje, há 23,3 milhões de pessoas que vivem abaixo da linha de pobreza, com rendimentos abaixo de $\mathrm{R} \$ 232$ por mês; cerca de $11,2 \%$ da população. A miséria subiu $33 \%$ nos últimos quatro anos. Trata-se de 6,3 milhões de novos pobres que foram adicionados ao estoque de pobreza. A PNAD revelou perda de renda de $7 \%$ em 2015. Enquanto a nova PNAD Contínua revelou queda de renda individual do trabalho, não ficando restrita somente aos ocupados. Entre os anos de 2015 e 2018, a renda média caiu 3,44\%. Esta perda foi mais forte entre os jovens (-20,1\% entre 15 e 19 anos e $-13,94 \%$ entre 20 e 24 anos), entre pessoas com ensino médio incompleto $(-11,65 \%)$, entre os responsáveis dos domicílios $(-10,38 \%)$ e regiões Norte ($6.08 \%)$ e Nordeste $(-6.43 \%)$. Ver: FGV (2018).
} 
Outro elemento recentemente observado é o impacto negativo da recessão, da informalidade e do desemprego na força da organização coletiva dos trabalhadores, o que torna mais difícil o enfrentamento contra as medidas regressivas do grande capital contra os trabalhadores. Em 2017, após a aprovação da Reforma Trabalhista, registrou-se piora do mercado de trabalho, reduzindo a capacidade de luta dos trabalhadores, pois a quantidade de greves registradas caiu para 1.566, o que significa uma queda de $25 \%$ em relação às duas mil greves anuais registradas em 2016 (DIEESE, 2018).

Em consonância com os ensinamentos de Mandel (1990) a classe trabalhadora deve estar pronta para defender arduamente suas conquistas, cada emprego ameaçado, lutando por bandeiras históricas e imediatas como a redução da jornada de trabalho para 40 horas sem redução de salários, reajustes salariais automáticos que reponham as perdas inflacionárias, aumentos reais e serviços públicos de qualidade. Além disso, o movimento sindical deve impulsionar a solidariedade com os setores mais atingidos pela crise - mulheres, imigrantes, jovens, velhos e desempregados.

O Piso Salarial Estadual é uma conquista da luta unificada dos sindicatos pela regulamentação e aplicação dos direitos sociais estabelecidos na Constituição Federal. Esses ganhos da economia política do trabalho contra o capital são chamados por Mészáros de ganhos defensivos. Eles melhoram parcialmente a condição de vida da classe trabalhadora e são aceitos nos limites do desenvolvimento do capital. Porém, na emergência de um tempo de crise estrutural do capital, as análises de Mészáros apontam para o fato de que não há margens para a continuidade cumulativa de ganhos defensivos, muito pelo contrário, o que nós estamos vendo é um esforço imenso do capital no sentido de anular ou regredir as conquistas sociais do proletariado.

\footnotetext{
Sendo assim, sob as condições de uma crise estrutural, ganhos defensivos normalmente bem acomodados nas margens de lucro em expansão - não são mais viáveis, e o objetivo da confrontação social se modifica radicalmente para contestar a alternativa hegemônica entre capital e trabalho na qualidade de modos diametralmente opostos de controle da reprodução social (MÉSZÁROS, 2002, p. 682).
}

Mészáros ensina que mesmo os ganhos defensivos são importantes e que a resistência e a luta fazem parte desta contradição capital e trabalho se manifestando em escala mundial, inclusive no Brasil.

\footnotetext{
Tais demandas têm sempre que provar a sua viabilidade no interior dos limites e determinações reguladoras preestabelecidos do sistema do capital. As partes só fazem sentido se puderem ser relacionadas ao todo ao qual pertencem objetivamente. Desse modo, é apenas nos termos de referências globais da alternativa hegemônica socialista à dominação do capital que a validade dos objetivos parciais estrategicamente escolhidos pode ser adequadamente julgada (MÉSZÁROS, 2002, p. 943).
}

Observa-se pelo nosso estudo que as conquistas de ganho real acima da inflação são modestas e refletem uma atuação defensiva do movimento sindical. Os salários ficam à mercê do processo inflacionário e necessitariam de ganhos reais mais vigorosos para a preservação duradoura do seu poder de compra. Contudo, entendemos que a manutenção do Piso Salarial Estadual, em Santa Catarina, é uma vitória da economia política do trabalho contra o capital, como uma medida defensiva para limitar a exploração do capital contra o

Temporalis, Brasília (DF), ano 19, n. 37, p. 118-133, jan./jun. 2019. | ISSN 2238-1856 
trabalho. Os valores estabelecidos em 2019 mostram-nos que a manutenção e a melhoria dos pisos salariais, por meio de conquista de ganhos reais frente a inflação, dependerão de uma maior mobilização das centrais sindicais durante as próximas negociações. Esperamos que este breve registro mostre a importância da luta histórica dos trabalhadores por melhores condições de vida e que novos estudos sejam realizados aprofundando a sistematização e a análise dos dados.

\section{REFERÊNCIAS}

BERTOLO, Katiuscia. Superexploração da força de trabalho no cotidiano e na vida dos sujeitos de direitos da política de assistência social em Santa Catarina. In: PAIVA, Beatriz Augusto (org.). Sistema Único de Assistência Social em Perspectiva: direitos, política pública e superexploração. São Paulo: Veras Editora, 2014.

BRASIL. Lei Complementar $\mathbf{n}^{\circ} \mathbf{1 0 3}$, de 14 de julho de 2000. Autoriza os Estados e o Distrito Federal a instituir o piso salarial a que se refere o inciso $V$ do art. $7^{\circ}$ da Constituição Federal, por aplicação do disposto no parágrafo único do seu art. 22. Disponível em: http://www.planalto.gov.br/ccivil_03/Leis/LCP/Lcp103.htm. Acesso em: 10 ago. 2015.

CARDOSO, José Álvaro. Salário mínimo e a negociação dos pisos estaduais. Florianópolis: DIEESE, 2015. Disponível em: <http://sindmecanicos.com.br/2015/01/12/post2465/>. Acesso em: 17 set. 2019 .

CARDOSO, José Álvaro. 0 fracasso da política econômica do golpe e a tentativa de esmagar as entidades sindicais. Florianópolis: DIEESE, 2019.

CONFEDERAÇÃO NACIONAL DA INDÚSTRIA. 101 Propostas para Modernização Trabalhista. Brasília: CNI, 2012.

DIEESE. Balanço das greves de 2017. Estudos e Pesquisas, n. 87, São Paulo, set. 2018. Disponível em:

https://www.dieese.org.br/balancodasgreves/2017/estPesq87balancoGreves2017.html. Acesso em: 17 set. 2019.

DIEESE. Boletim de Conjuntura. São Paulo, n. 3, maio, 2015a. Disponível em: https://www.dieese.org.br/boletimdeconjuntura/2015/boletimConjuntura003.html. Acesso em: 17 set. 2019 .

DIEESE. Greves 2013: informações preliminares. São Paulo: DIEESE, 2015b.

DIEESE. Pesquisa Nacional da Cesta Básica de Alimentos Salário mínimo nominal e necessário. São Paulo, atualizado até 2019. Disponível em:

http://www.dieese.org.br/analisecestabasica/salarioMinimo.html. Acesso em: 17 set. 2019.

DIEESE. A situação do trabalho no Brasil na primeira década dos anos 2000. São Paulo: DIEESE, 2012. 
FECESC. Piso Salarial: Representantes dos trabalhadores solicitam audiência com governador. FECESC, Florianópolis, 22 fev. 2019a. Disponível em: http://www.fecesc.org.br/representantes-dos-trabalhadoressolicitam-audiencia-com-governador-sobre-piso-salarial-estadual/. Acesso em: 05 mar. 2019.

FECESC. Deputados aprovam Projeto que reajusta o Piso Salarial Estadual em 2019. FECESC, Florianópolis, 2019b. Disponível em: http://www.fecesc.org.br/deputadosaprovam-projeto-que-reajusta-43-o-piso-salarial-estadual-em-2019/. Acesso em: 17 set. 2019.

FECESC. SC tem novos pisos salariais para 2019 - Lei complementar n. 740, de 05 de abril de 2019. FECESC, 6 abr. 2019c. Disponível em: http://www.fecesc.org.br/sc-tem-novospisos-salariais-para-2019-lei-complementar-n-740-de-5-de-abril-de-2019/. Acesso em: 27 jun. 2019.

FECESC. Saiba os valores do Piso Salarial Estadual para 2018. Florianópolis, 2018. Disponível em: http://www.fecesc.org.br/saiba-os-valores-do-piso-salarial-estadual-para2018/. Acesso em 15 mar. 2019.

FECESC. Piso Salarial Estadual tem valores definidos para 2017. Florianópolis, 2 mar.2017. Disponível em: http://www.fecesc.org.br/piso-salarial-estadual-tem-valores-definidos-para-2017l. Acesso em:05 mar. 2019.

FECESC. Fechado acordo sobre o reajuste do Piso Estadual de Salários de SC. Florianópolis: 22 mar. 2016. Disponível em: http://www.fecesc.org.br/fechado-acordo-sobre-o-reajuste-do-piso-estadual-desalarios-de-sc/. Acesso em: 05 mar. 2019.

FECESC. Definido o reajuste do Piso Salarial Estadual catarinense em 2015. Florianópolis, 30 jan. 2015a. Disponível em: http://www.fecesc.org.br/noticias.php?id=6330. Acessado em: 29 jun. 2015.

FECESC. Governador sanciona lei de reajuste do Piso Salarial Estadual para 2015. Florianópolis, 27 mar. 2015b. Disponível em: http://www.fecesc.org.br/noticias.php?id=6389. Acesso em: 06 jul. 2015.

FGV. Pobreza e desigualdade aumentaram nos últimos 4 anos no Brasil, revela estudo. Notícias, Rio de Janeiro, 10 set. 2018. Disponível em: https://portal.fgv.br/noticias/pobreza-e-desigualdade-aumentaram-ultimos-4-anosbrasil-revela-estudo. Acesso em: 05 mar. 2019.

HOMRICH, Sérgio. Fechado acordo que reajusta o Piso Salarial Estadual em 2019. Florianópolis: DIEESE, 2019. Disponível em: http://www.fecesc.org.br/fechado-acordoque-reajusta-o-piso-salarial-estadual-em-2019/. Acesso em 17 set. 2019.

IBGE. Índice nacional de preços ao consumidor - INPC. Portalbrasil.net, Brasílias (DF), atualizado em 2019. Disponível em: http://www.portalbrasil.net/inpc.htm. Acesso em: 5 mar. 2019.

IAMAMOTO, Marilda Vilela. Serviço social em tempo de capital fetiche: capital financeiro, trabalho e questão social. 2. ed. São Paulo: Cortez, 2008. 
IAMAMOTO, Marilda Vilela. Relações sociais e serviço social no Brasil. 41. ed. São Paulo: Cortez, 1982.

KOVAL, Boris. História do proletariado brasileiro (1857-1967). São Paulo: Alfa-Omega, 1982.

LINHARES, Hermínio. Contribuição à história das lutas operárias no Brasil. 2. ed. São Paulo: Alfa-Ômega, 1977, p. 33.

MATTOS, Marcelo Badaró. Escravizados e livres: experiências comuns na formação da classe trabalhadora carioca. Rio de Janeiro: Bom Texto, 2008.

MARX, Karl. O capital. Livro III. Vol. IV. Rio de Janeiro, Difel, 1983.

MARX, Karl. O capital. Livro I. Vol. I. Rio de Janeiro, Difel, 1996.

MARX, Karl. Salário, Preço e Lucro. São Paulo: Global, 1987.

MANDEL, Ernest. A crise do capital. Os fatos e sua interpretação marxista. São Paulo: Ensaio, 1990.

MARINI, Rui Mauro. Dialética da dependência. Petrópolis: Vozes, 2000.

MÉSZÁROS, István. Para além do capital. São Paulo: Boitempo, 2002.

NASCIMENTO, Amauri Mascaro do. Curso de direito do trabalho: história e teoria geral do direito do trabalho: relações individuais e coletivas do trabalho. 25. ed. São Paulo: Saraiva, 2010.

ROSSI, Valdemar; GERAB, William Jorge. Para entender os sindicatos no Brasil: uma visão classista. São Paulo: Expressão Popular, 2009.

SALÁRIO mínimo em janeiro deveria ser de R\$3.928,73, diz DIEESE. UOL, notícias, 6 fev. 2019. Disponível em: https://www.bol.uol.com.br/noticias/2019/02/06/salario-minimoideal-em-janeiro-dieese.htm?cmpid=copiaecola. Acesso em: 5 mar. 2019.

SANTA CATARINA. Lei complementar do Estado de Santa Catarina n 459 de 30.09.2009. Institui no âmbito do Estado de Santa Catarina pisos salariais para os trabalhadores que especifica e adota outras providências. Diário Oficial do Estado (DOE-SC), Florianópolis, 30 set. 2009. Disponível em:

http://www.normaslegais.com.br/legislacao/lcsc459_2009.htm. Acesso em: 29 jun. 2015.

SEVERO, Valdete Nunes. A hermenêutica trabalhista e o princípio do trabalho. In: SOUTO MAIOR, Jorge Luiz; SEVERO, Valdete Souto. Resistência: aportes teóricos contra o retrocesso trabalhista. São Paulo: Expressão Popular, 2017. 
SILVA, José Antonio Ribeiro de Oliveira. A flexibilização da jornada de trabalho e seus reflexos na saúde do trabalhador. In: NAVARRO, V.L.; SOUZA, E. A. (org.). O Avesso do Trabalho III. São Paulo: Expressão Popular, 2013.

SILVA, Mauri Antônio. Consequências da crise do capital sobre a classe trabalhadora (1990 a 2016). 2017. Tese (Doutorado em Serviço Social)- Universidade Federal de Santa Catarina, Florianópolis, 2017.

SINGER, André. A (falta) de base política para o ensaio desenvolvimentista. In: SINGER, André; LOUREIRO, Isabel (org.). As contradições do lulismo: a que ponto chegamos? São Paulo: Boitempo, 2016.

SOUTO MAIOR, Jorge Luiz. Curso de direito do trabalho: teoria geral do direito do trabalho. vol. I. Parte I. São Paulo: LTR, 2011.

TEIXEIRA, Marilane Oliveira [et al.]. Contribuição crítica à reforma trabalhista. Campinas: UNICAMP/IE/CESIT, 2017. 328 p.

VALENCIA, Adrián Sotelo. Crisis capitalista y desmedida del valor. Um enfoque desde los grundrisse. México: Universidad Autónoma Nacional de México/Itaca, 2010. 